\title{
Prevalence and Clinicopathological Significance of MET Overexpression and Gene Amplification in Patients with Gallbladder Carcinoma
}

\section{Yeseul Kim, MD, PhD \\ Seong Sik Bang, MD \\ Seungyun Jee, MD \\ Sungeon Park, MD \\ Su-Jin Shin, MD, PhD \\ Kiseok Jang, MD, PhD}

Department of Pathology, Hanyang

University College of Medicine, Seoul, Korea
Correspondence: Kiseok Jang, MD, PhD

Department of Pathology, Hanyang University

College of Medicine, 222 Wangsimni-ro,

Seongdong-gu, Seoul 04763, Korea

Tel: $82-2-2290-8248$

Fax: 82-2-2296-7502

E-mail: medartisan@hanyang.ac.kr

Received July 2, 2019

Accepted October 23, 2019

Published Online October 24, 2019

\section{Purpose}

Mesenchymal epithelial transition (MET) is a proto-oncogene that encodes a heterodimeric transmembrane receptor tyrosine kinase for the hepatocyte growth factor. Aberrant MET signaling has been described in several solid tumors-especially non-small cell lung cancer-and is associated with tumor progression and adverse prognosis. As MET is a potential therapeutic target, information regarding its prevalence and clinicopathological relevance is crucial.

\section{Materials and Methods}

We investigated MET expression and gene amplification in 113 gallbladder cancers using tissue microarray. Immunohistochemistry was used to evaluate MET overexpression, and silver/fluorescence in situ hybridization (ISH) was used to assess gene copy number.

\section{Results}

MET overexpression was found in 37 cases of gallbladder carcinoma (39.8\%), and gene amplification was present in 17 cases (18.3\%). MET protein expression did not correlate with MET amplification. MET amplification was significantly associated with aggressive clinicopathological features, including high histological grade, advanced pT category, lymph node metastasis, and advanced American Joint Committee on Cancer stage. There was no significant correlation between any clinicopathological factors and MET overexpression. No difference in survival was found with respect to MET overexpression and amplification status.

\section{Conclusion}

Our data suggested that MET might be a potential therapeutic target for targeted therapy in gallbladder cancer, because MET amplification was found in a subset of tumors associated with adverse prognostic factors. Detection of MET amplification by ISH might be a useful predictive biomarker test for anti-MET therapy.

\section{Introduction}

Gallbladder cancer (GBC) is a relatively rare primary malignancy, but it is the most common malignant neoplasm of the biliary tract, and one of the most aggressive cancers of the biliary tract with poor prognosis [1]. A variety of genetic and epigenetic alterations are associated with GBC, involving tumor suppressor genes, oncogenes, and DNA repair genes.
Key words

Gallbladder cancer, Gene amplification, Gene copy number, In situ hybridization, Immunohistochemistry, MET 
ERBB3. Moreover, ErbB signaling, including EGFR, ERBB2, ERBB3, ERBB4, and their downstream genes is the most extensively mutated pathway, affecting $36.8 \%$ of patients with GBC. Although cytotoxic chemotherapy with the combination of gemcitabine and cisplatin has been accepted as the first-line therapy, the patient outcome is still disappointing. After ErbB signaling pathway was found to be one of the pathways contributing to gallbladder carcinoma, target-oriented agents, including monoclonal antibodies and tyrosine kinase inhibitors against EGFR and vascular endothelial growth factor have entered clinical trials $[4,5]$. However, as those clinical trials revealed no, or marginal benefits, novels targets are needed to improve the patient outcomes.

The mesenchymal epithelial transition (MET) receptor tyrosine kinase pathway is one of the most commonly activated signaling pathways in primary human cancers. MET has a heterodimeric structure composed of an extracellular $\alpha$ subunit and a $\beta$ chain that contains an extracellular domain, a transmembrane segment, and an intracellular tyrosine kinase region [6]. Activation of MET signaling has a critical role not only in tumor formation, progression, angiogenesis, and metastasis, but is also involved in mediating resistance against other targeted treatments $[7,8]$. Hepatocyte growth factor (HGF), a ligand of MET, stimulates the tyrosine kinase activity of MET and activates multiple downstream signaling pathways, including the Grb2-Ras-mitogen-activated protein kinase (MAPK) cascade, the phosphatidylinositol-3 kinase (PI3K) pathway, the Wnt / $\beta$-catenin pathway, and the signal transducer and activator of transcription (STAT) pathway [9]. Dysregulation of MET protein has been reported in a variety of human malignancies and premalignant lesions, including hepatocellular carcinoma (HCC) and non-small cell lung cancer (NSCLC) [10,11]. Accordingly, the possibility of targeting the $M E T$ gene in different cancer types is now being evaluated in clinical trials. Several drugs have been developed that target MET or HGF. These agents are divided into small molecule inhibitors and monoclonal antibodies. The small molecule tyrosine kinase inhibitors are further subdivided into multiple kinases and selective MET inhibitors. Crizotinib and cabozantinib are examples of multikinase MET inhibitors. Selective MET inhibitors include capmatinib and tepotinib. Monoclonal antibody therapy is divided into anti-MET antibodies, such as onartuzumab and emibetuzumab, and anti-HGF antibodies, including ficlatuzumab and rilotumumab [12].

As MET is a potential therapeutic target, information regarding its prevalence and clinicopathological relevance is important. However, the prevalence of MET overexpression and gene amplification in GBCs and its clinicopathological significance is not yet known precisely. Therefore, this study evaluated the expression level and gene copy number of MET in GBC tissues and their correlations with various clin- icopathological characteristics, including patient's prognosis.

\section{Materials and Methods}

\section{Patients and specimens}

We examined 116 GBC samples (113 patients) obtained from consecutive surgical procedures performed at the Hanyang University Hospital between 1991 and 2016. Three patients had synchronous tumors in the gallbladder. The GBCs were assessed according to the system for staging primary tumor/regional lymph nodes/distant metastasis (TNM) described in the 8th American Joint Committee on Cancer (AJCC) cancer staging manual and histological classification according to the World Health Organization classification of tumors. The clinical data were retrospectively obtained from electronic medical records and included age at diagnosis, sex, pathological profiles (size, stage, histological grade, location, margin status, lymphovascular invasion, and perineural invasion), metastasis, recurrence, and date of death. Tumor recurrence was defined as tumor growth in any site of the body after the surgery, which was diagnosed clinically, radiologically, or pathologically, but mainly by computed tomography and ultrasonography. Among the 113 patients, $44(37.9 \%)$ were men, and the median age was 63.5 years (range, 28 to 90 years). The tumor types of gallbladder were as follows: adenocarcinoma $(n=109)$, squamous carcinoma $(n=2)$, adenosquamous carcinoma $(n=4)$, and small cell carcinoma $(n=1)$. The detailed clinicopathological features are described in Table 1.

\section{Tissue microarray construction}

Hematoxylin and eosin slides made from formalin-fixed paraffin-embedded tissue blocks were reviewed, and the most representative tumor regions without necrosis and hemorrhage were carefully selected and marked. Single tissue cores, each $3.0 \mathrm{~mm}$ in diameter, were punched from each paraffin block and assembled into a new recipient paraffin block using a manual tissue microarray (TMA) instrument (Quick-Ray, Unitma, Seoul, Korea). A total of four TMA blocks were constructed.

\section{Immunohistochemistry}

Immunohistochemical staining (IHC) was performed on Ventana BenchMark XT autostainer (Ventana Medical Systems, Tucson, AZ), according to the manufacturer's protocol. 
Table 1. Histological and clinical characteristics of gallbladder cancer patients

\begin{tabular}{|c|c|}
\hline Clinicopathological characteristic & No. $(\%)$ \\
\hline \multicolumn{2}{|l|}{ Age (yr) } \\
\hline$<65$ & $60(53.1)$ \\
\hline$\geq 65$ & $53(46.9)$ \\
\hline \multicolumn{2}{|l|}{ Sex } \\
\hline Male & $44(38.9)$ \\
\hline Female & $69(61.1)$ \\
\hline \multicolumn{2}{|l|}{ Histological type } \\
\hline Adenocarcinoma & $109(94.0)$ \\
\hline Squamous & $2(1.7)$ \\
\hline Adenosquamous & $4(3.4)$ \\
\hline Small cell neuroendocrine & $1(0.9)$ \\
\hline \multicolumn{2}{|l|}{ Histological grade } \\
\hline In situ & $6(5.5)$ \\
\hline Well & $26(23.9)$ \\
\hline Moderate & $50(45.9)$ \\
\hline Poor & $27(24.8)$ \\
\hline \multicolumn{2}{|l|}{ T category } \\
\hline Tis & $6(5.3)$ \\
\hline T1a & $8(7.1)$ \\
\hline $\mathrm{T} 1 \mathrm{~b}$ & $8(7.1)$ \\
\hline $\mathrm{T} 2$ & $46(40.7)$ \\
\hline T3 & $37(32.7)$ \\
\hline $\mathrm{T} 4$ & $8(7.1)$ \\
\hline \multicolumn{2}{|l|}{ AJCC stage } \\
\hline 0 & $6(5.3)$ \\
\hline I & $16(14.2)$ \\
\hline II & $31(27.4)$ \\
\hline III & $44(38.9)$ \\
\hline IV & $16(14.2)$ \\
\hline \multicolumn{2}{|l|}{ Lymph node metastasis } \\
\hline N0 & $56(57.1)$ \\
\hline N1 & $31(31.6)$ \\
\hline $\mathrm{N} 2$ & $11(11.2)$ \\
\hline \multicolumn{2}{|l|}{ Distant metastasis } \\
\hline M0 & $103(91.2)$ \\
\hline M1 & $10(8.8)$ \\
\hline \multicolumn{2}{|l|}{ Lympho-vascular invasion } \\
\hline Absent & $58(64.3)$ \\
\hline Present & $55(35.7)$ \\
\hline \multicolumn{2}{|l|}{ Perineural invasion } \\
\hline Absent & $72(63.7)$ \\
\hline Present & $41(36.3)$ \\
\hline
\end{tabular}

AJCC, American Joint Committee on Cancer.

The primary antibody used was anti-MET (clone sp44) rabbit monoclonal antibody (Ventana Medical Systems).

Two pathologists (K.J. and Y.K.) independently evaluated MET IHC. The immunoreactivity was scored using a four- tier system, which has been established in previous studies on MET IHC scoring system in NSCLC [13]. This system was used to evaluate both proportion and staining intensity: 0 , no staining or $<50 \%$ tumor cells with any intensity; $1+, \geq 50 \%$ of tumor cells staining with weak or higher staining but $<50 \%$ with moderate or higher strong intensity; $2+, \geq 50 \%$ of tumor cells with moderate or higher staining but $<50 \%$ with strong intensity; $3+, \geq 50 \%$ of tumor cells staining with strong intensity. Samples exhibiting $2+$ or $3+$ immunostaining were considered positive for MET overexpression.

\section{In situ hybridization}

MET silver in situ hybridization (SISH) was performed on an automated Ventana BenchMark XT platform (Ventana Medical Systems), according to the manufacturer's protocols and using both MET-specific and centromere 7 (CEP7)-specific probes. Fluorescence in situ hybridization (FISH) was used to confirm MET-amplified cases by SISH. FISH was performed using Zytolight SPEC MET/CEN7 Dual color probe (Zytovision, Bremerhaven, Germany), according to the manufacturer's protocol.

The gene copy number was assessed independently by two pathologists (K.J. and Y.K.) and the number of MET and CEP7 signals was counted in at least 40 tumor cell nuclei in "hot spot" area (80 nuclei if there was no agreement). Then, the mean number of MET and CEP7 copies per nuclei and the MET/CEP7 ratio was calculated. We used the four different scoring systems for in situ hybridization (ISH) interpretation.

- Method A: High-level amplification was defined in tumors with a MET/CEP7 ratio $\geq 2.0$, an average MET gene copy number per cell of $\geq 6.0$, or $\geq 10 \%$ of tumor cells containing $\geq 15$ MET signals. Intermediate level of gene copy number gain being defined as $\geq 50 \%$ of cells containing $\geq 5$ MET signals and criteria for high-level amplification are not fulfilled. Low level of gene copy number gain was defined as $\geq 40 \%$ of tumor cells showing $\geq 4$ MET signals and criteria for high-level amplification or intermediate level of gene copy number gain are not fulfilled. All other tumors were classified as negative [14].

- Method B: Tumors with a mean gene copy number of $\geq 5$ MET signals per tumor cell were classified as MET amplification [15].

- Method C: Tumors with a MET/CEP7 ratio $\geq 2$ were defined as MET amplification by PathVysion [16,17].

- Method D: High-level amplification (presence of loose or tight clusters of MET signals too numerous to count) was defined in tumors with MET/CEP7 ratio more than 5.0. Low-level amplification was defined in tumors with MET / CEP7 ratio $\geq 2.2$ and $\leq 5.0$ [18]. 


\section{Targeted sequencing by Oncomine comprehensive assay}

DNA and total RNA were extracted by using RecoverAll Multi-Sample RNA/DNA Isolation Workflow (Invitrogen, Waltham, MA) according to the manufacturer's instructions. Library preparation for each sample was performed using the multiplex PCR-based Ion Torrent AmpliSeq technology (Thermo Fisher Scientific, Waltham, MA), together with the Oncomine comprehensive assay (OCA) v1 panel (Thermo Fisher Scientific) according to the manufacturer's protocol. OCA v1 panel covers multiple exons in 143 genes with 156 amplicons. Next generation sequencing (NGS) was performed on the Ion Torrent S5XL using an Ion 540 chip (PGM, Life Technologies, Grand Island, NE). Results were analyzed using the Variant caller by aligning the reads to the hg19 reference genome, calling the variants, and generating an interactive report for visualization and quality control. Data analysis was performed using Ion Reporter Server hosting informatic tools (Ion Reporter Software v5.0) for variant analysis, filtering, and annotations.

\section{Statistical analysis}

To analyze the association between the clinicopathological features and MET gene copy number status as well as MET protein expression, chi-square test was employed. Diseasefree survival and overall survival (OS) were determined using Kaplan-Meier survival curves, and the log-rank test was used to compare the differences. The Cox proportional hazard regression model was used to evaluate the independent prognostic significance. All statistical analyses were carried out using SPSS for Windows ver. 19.0 software (SPSS Inc., Chicago, IL), and $\mathrm{p}<0.05$ was considered as statistically significant.

\section{Ethical statement}

This study was approved by the Institutional Review Board of Hanyang University Hospital (IRB No. 2018-08-031002). Waiver of informed consent for this study was obtained from IRB based on the retrospective analyses of archived tissues and clinical data.

\section{Results}

\section{MET overexpression and gene amplification in GBCs}

MET IHC was successfully performed in 93/116 tissue cores $(80.2 \%)$. The unsuccessful staining was mainly due to empty TMA cores or absence of tumor cells. Many tissue cores showed focal or diffuse cytoplasmic/membranous staining pattern with varying intensity. MET IHC score 0-3 was observed in $26(28.0 \%), 30(32.3 \%), 22(23.7 \%)$, and 15 $(16.1 \%)$ tumors, respectively. MET overexpression, defined by IHC score 2 or more, was found in $37 / 93$ (39.8\%) GBC tumor tissues (Fig. 1).

SISH was successful in 93/116 tissue cores $(80.2 \%)$, and $17 / 93(18.3 \%), 9(9.7 \%), 12(12.9 \%)$, and $11(13.4 \%)$ showed $M E T$ gene amplification according to four different interpretation methods (Table 2). FISH was performed in same TMA sections and all cases showed concordant results with SISH. The representative images of SISH and FISH are shown in Fig. 2.

To identify the intratumoral heterogeneity of MET copy number, we performed ISH on whole tissue sections in subset of amplified cases (6 out of 17 cases). Because the assessment of heterogeneity is difficult on FISH slide due to dark field, we performed bright field SISH to observe morpho-
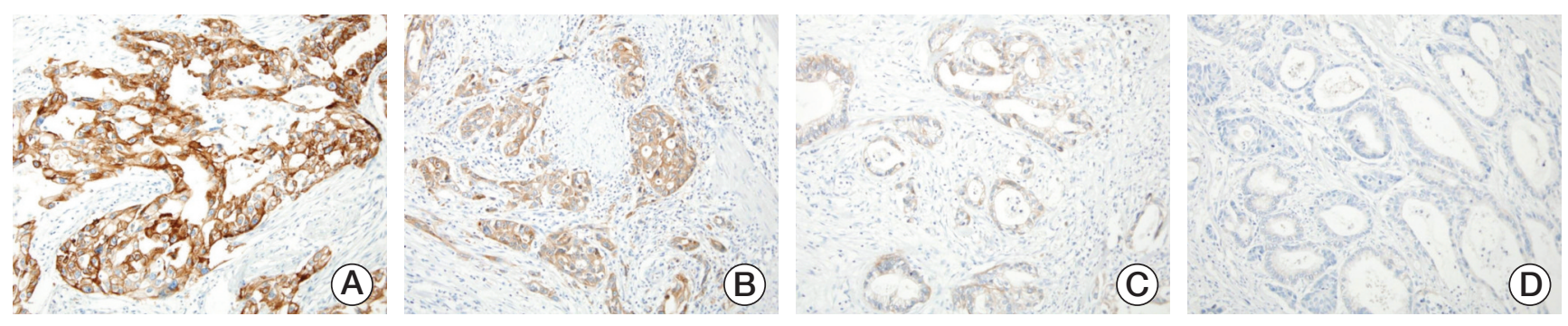

Fig. 1. Representative sections of immunohistochemical (IHC) scores for MET expression in gallbladder cancers ( $\times 400)$. (A) IHC score 3, strong cytoplasmic/membranous staining in almost all tumor cells. (B) IHC score 2, more than 50\% of tumor cells with moderate staining intensity but $<50 \%$ strong intensity. (C) IHC score 1, weak staining in more than $50 \%$ of tumor cells. (D) IHC score 0 , no staining observed in invasive tumor cells. 
Table 2. Prevalence of $M E T$ amplification in gallbladder cancers according to different interpretation criteria

\begin{tabular}{|c|c|c|c|c|}
\hline & Reference & Classification & No. & No. of amplified cases $(\%)$ \\
\hline \multirow[t]{4}{*}{ Method A } & Schildhaus et al. [14] & High & 12 & $17(18.3)$ \\
\hline & & Intermediate & 0 & \\
\hline & & Low & 5 & \\
\hline & & Negative & 76 & \\
\hline \multirow[t]{2}{*}{ Method B } & Cappuzzo et al. [15] & Positive & 9 & $9(9.7)$ \\
\hline & & Negative & 84 & \\
\hline \multirow[t]{2}{*}{ Method C } & PathVision $[16,17]$ & Positive & 12 & $12(12.9)$ \\
\hline & & Negative & 81 & \\
\hline \multirow[t]{3}{*}{ Method D } & Ou et al. [18] & High & 0 & $11(13.4)$ \\
\hline & & Low & 11 & \\
\hline & & Negative & 82 & \\
\hline
\end{tabular}
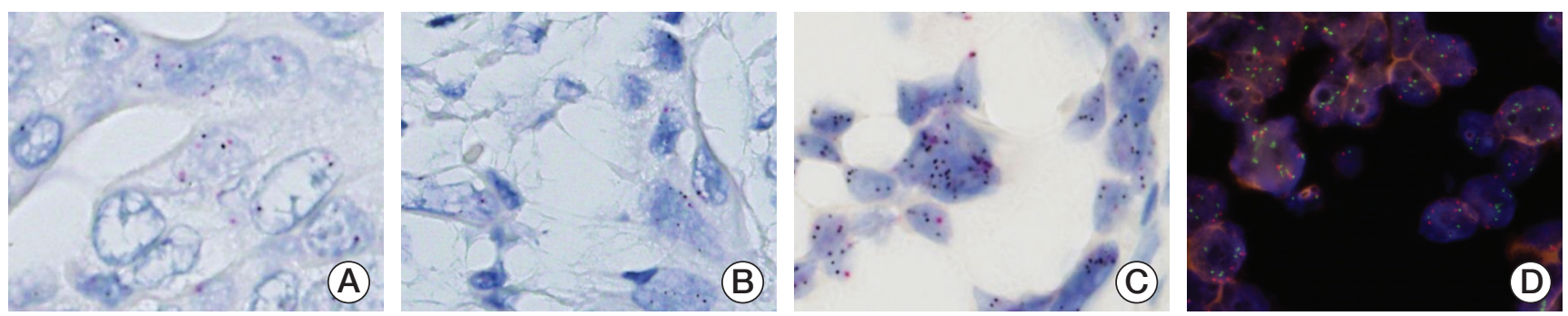

Fig. 2. Representative sections of silver in situ hybridization (SISH) and fluorescence in situ hybridization (FISH) analyses of MET/ centromere 7 (CEP7) (×1,000). (A) SISH, no MET amplification, 1-2 MET gene signals (black), and 1-2 CEP7 signals (red) were present in each nucleus. (B) SISH, low-grade MET copy number gain, 2-7 MET gene signals (black), and 1-2 CEP7 (red) were present in each nucleus. (C) SISH, high-level amplification, 7-8 or more MET gene signals (black), and 1-5 CEP7 (red) were present in each nucleus. (D) FISH, high-level amplification, 5-10 or more MET gene signals (green), and 4-5 CEP7 (red) were present in each nucleus.
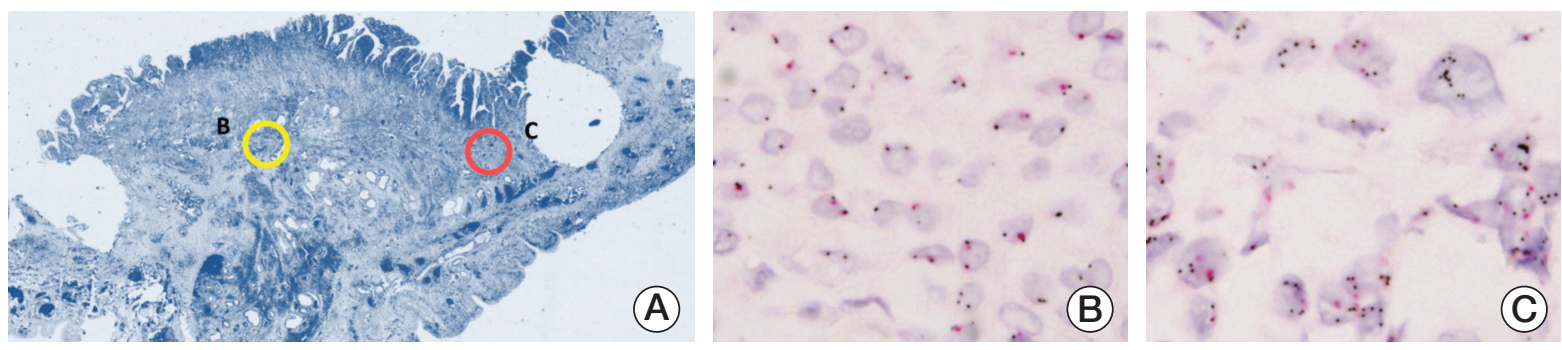

Fig. 3. Representative section of silver in situ hybridization on whole section. (A) Yellow and red circle highlight the nonamplified lesion and amplified lesion, respectively. (B) The tumor cells exhibit 1-2 c-MET gene signals (black), and 1-2 centromere 7 signals (red) in each nucleus. (C) In the amplified lesion, tumor cells exhibit 4-12 c-MET gene signals $(\times 1,000)$.

logic detail. As we expected, intratumor heterogeneity of MET copy number was found within the tumors (Fig. 3).

Tumors with high-level MET amplification tended to express higher MET protein expression than those with low- level copy number gain or no copy number gain (S1 Table). MET gene copy number was marginally higher for MET overexpressed tumors. (mean MET gene copy number, 2.2 vs. 1.9). However, no statistically significant correlation was 


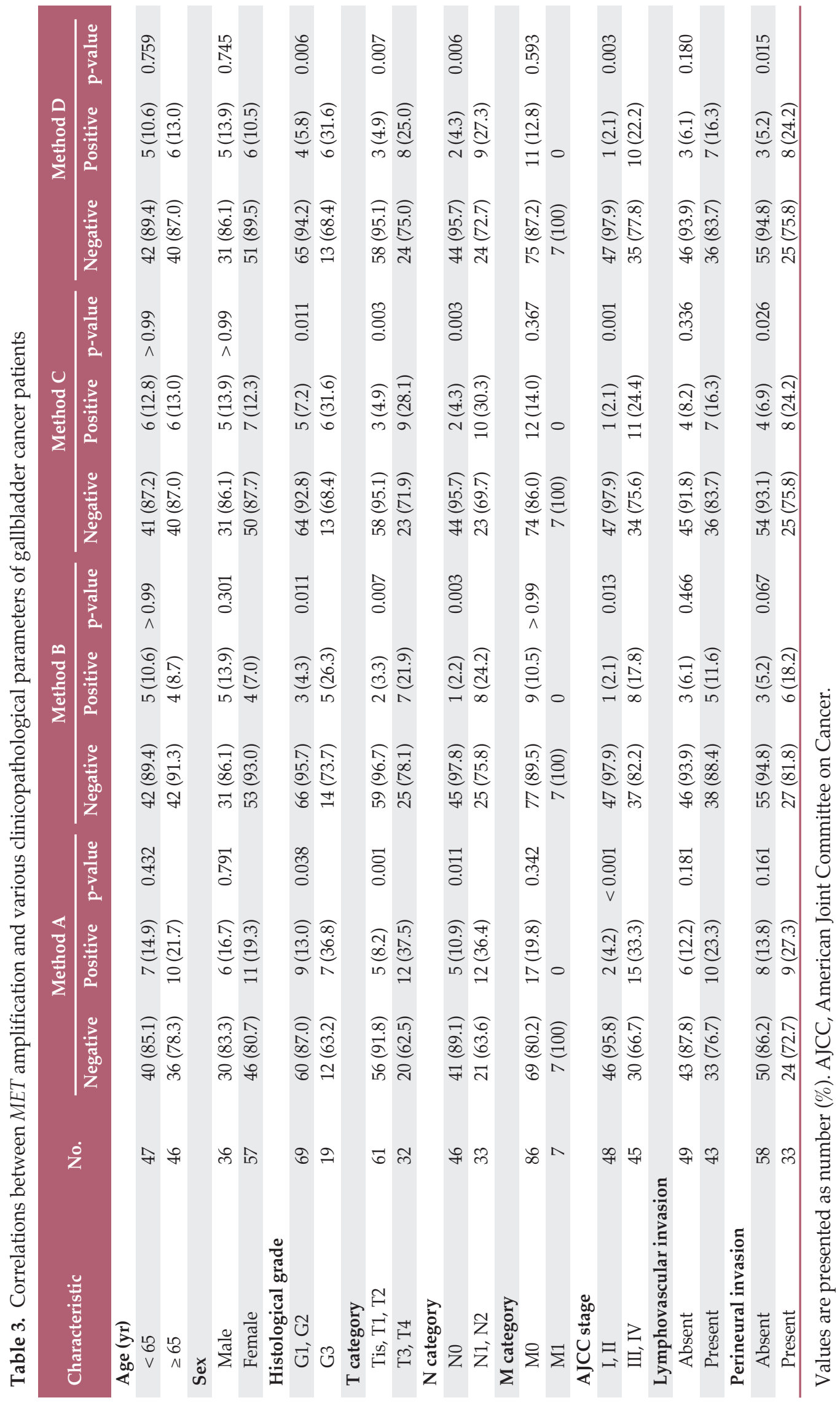


Table 4. Univariate Cox regression analysis of variables related to the prognosis of gallbladder cancer

\begin{tabular}{|c|c|c|c|c|c|c|}
\hline \multirow{2}{*}{ Variable } & \multicolumn{3}{|c|}{ Recurrence-free survival } & \multicolumn{3}{|c|}{ Overall survival } \\
\hline & HR & $95 \% \mathrm{CI}$ & p-value & HR & $95 \% \mathrm{CI}$ & p-value \\
\hline Age $(<65$ yr vs. $\geq 65$ yr $)$ & 1.075 & $0.687-1.682$ & 0.750 & 1.388 & $0.870-2.214$ & 0.169 \\
\hline Sex (male vs. female) & 1.324 & $0.830-2.112$ & 0.239 & 1.206 & $0.745-1.953$ & 0.447 \\
\hline Histologic grade (G1, G2 vs. G3) & 1.698 & $0.923-3.122$ & 0.088 & 0.813 & $1.263-2.604$ & 0.001 \\
\hline T category (Tis, T1, T2 vs. T3, T4) & 2.464 & $1.565-3.880$ & $<0.001$ & 2.539 & $1.575-4.093$ & $<0.001$ \\
\hline Lymph node metastasis (N0 vs. N1, N2) & 2.462 & $1.470-4.124$ & 0.001 & 2.749 & $1.584-4.769$ & $<0.001$ \\
\hline Distant metastasis (M0 vs. M1) & 5.639 & 2.733-11.639 & $<0.001$ & 6.157 & $2.984-12.703$ & $<0.001$ \\
\hline AJCC stage (I, II vs. III, IV) & 2.705 & $1.681-4.353$ & $<0.001$ & 2.870 & $1.731-4.759$ & $<0.001$ \\
\hline Lymphovascular invasion (absent vs. present) & 2.457 & $1.545-3.909$ & $<0.001$ & 2.753 & $1.698-4.464$ & $<0.001$ \\
\hline Perineural invasion (absent vs. present) & 3.045 & $1.856-4.994$ & $<0.001$ & 3.643 & $2.185-6.071$ & $<0.001$ \\
\hline$M E T$ amplification (absent vs. present) ${ }^{a)}$ & 1.299 & $0.668-2.525$ & 0.299 & 1.667 & $0.868-3.202$ & 0.125 \\
\hline MET overexpression (score 0-1 vs. score 2-3) & 0.935 & $0.587-1.490$ & 0.777 & 1.040 & $0.641-1.688$ & 0.873 \\
\hline
\end{tabular}

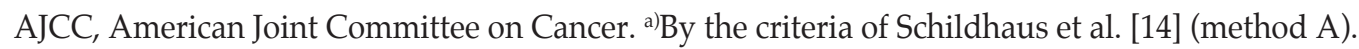

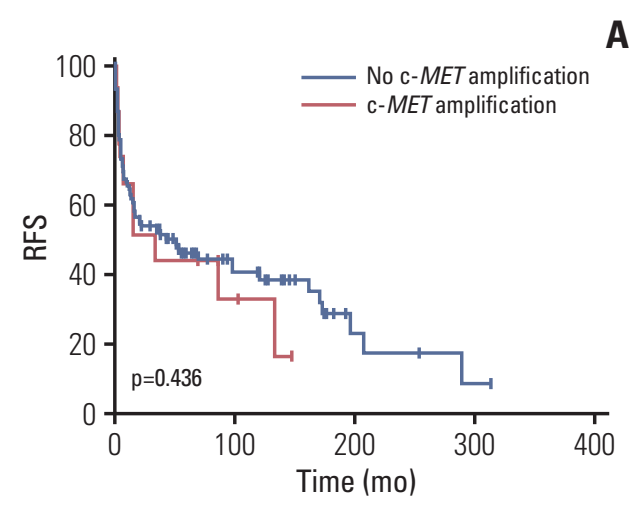

A

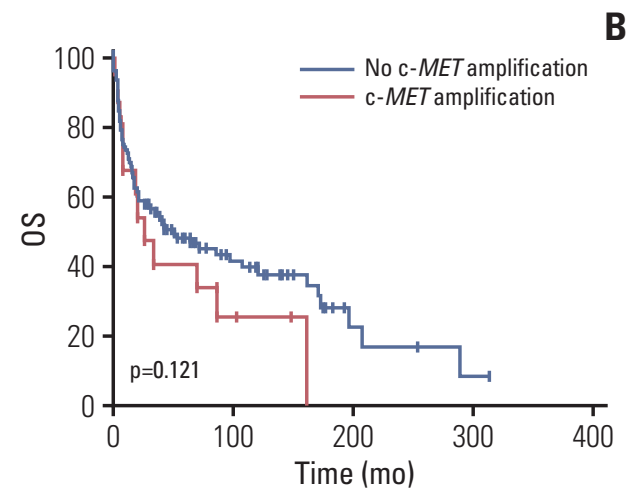

Fig. 4. Kaplan-Meier survival curves of gallbladder cancer patients stratified on the basis of MET amplification status. (A) Recurrence-free survival (RFS) according to $M E T$ amplification (log-rank test, $\mathrm{p}=0.436$ ). (B) Overall survival (OS) according to $M E T$ amplification (log-rank test, $\mathrm{p}=0.121$ ).

found between MET protein overexpression and gene copy number changes.

Targeted sequencing data was available in 17 cases. MET copy number ranged from 0 to 9.9 (mean, 2.53). No METamplified case was detected by NGS method in all 17 cases (S2 Table).

\section{Correlation between MET overexpression/amplification and clinicopathological characteristics in GBCs}

MET protein expression by immunohistochemistry, including the proportion of positive tumor cells, the staining intensity, and IHC scores, were not correlated with any clinicopathological characteristics (S3 Table).

MET amplification by the criteria of Schildhaus et al. [14] (method A) significantly correlated with higher histological grade $(\mathrm{p}=0.038)$, advanced $\mathrm{T}$ category $(\mathrm{p}=0.001)$, frequent lymph node metastasis ( $\mathrm{p}=0.011)$, and advanced AJCC stage $(\mathrm{p}<0.001)$. MET-amplified tumors by the criteria of Cappuzzo et al. [15] (method B) showed higher histological grade $(\mathrm{p}=0.011)$, advanced $\mathrm{T}$ category $(\mathrm{p}=0.007)$, frequent lymph node metastasis ( $\mathrm{p}=0.003)$, and advanced AJCC stage $(\mathrm{p}=0.013)$. MET amplification by the criteria of PathVysion $[16,17]$ (method C) correlated with higher histological grade $(\mathrm{p}=0.011)$, advanced T category ( $\mathrm{p}=0.003)$, frequent lymph node metastasis $(\mathrm{p}=0.003)$, presence of perineural invasion $(\mathrm{p}=0.026)$, and advanced AJCC stage $(\mathrm{p}=0.001)$. MET amplification by the criteria of Ou et al. [18] (method D) correlated with higher histological grade $(\mathrm{p}=0.006)$, advanced $\mathrm{T}$ category $(\mathrm{p}=0.007)$, frequent lymph node metastasis $(\mathrm{p}=0.006)$, presence of per- 


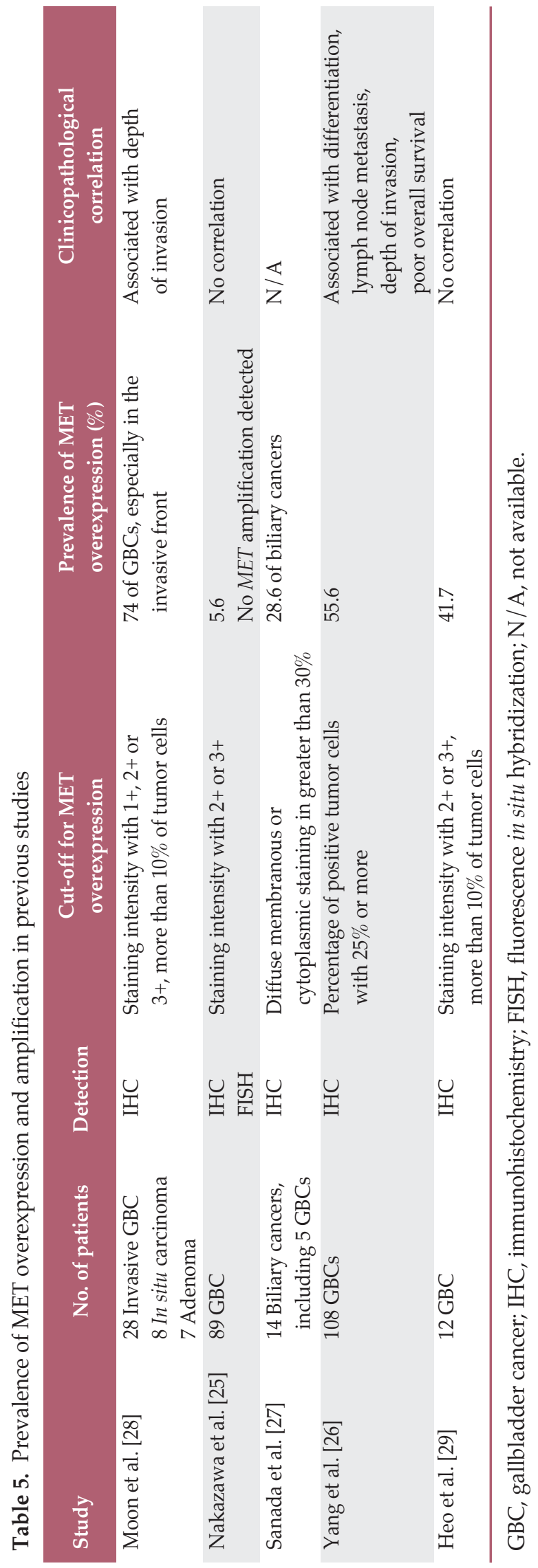

ineural invasion $(\mathrm{p}=0.015)$, and advanced AJCC stage $(\mathrm{p}=0.003)$ (Table 3).

\section{Survival analysis of MET expression and gene amplifi- cation in GBCs}

The median recurrence-free survival (RFS) and OS for all patients were 38.6 months and 64.7 months, respectively. Survival analyses were performed to evaluate the conventional pathological prognostic factors of our cohort. Histological grade ( $\mathrm{p}=0.088$ and $\mathrm{p}=0.001$ ), advanced $\mathrm{T}$ stage (both $\mathrm{p}<0.001$ ), lymph node metastasis ( $\mathrm{p}=0.001$ and $\mathrm{p}<0.001$ ), distant metastasis (both $\mathrm{p}<0.001$ ), advanced AJCC stage (both $\mathrm{p}<0.001$ ), lymphovascular invasion (both $\mathrm{p}<0.001$ ), and perineural invasion (both $\mathrm{p}<0.001$ ) were revealed as predictors of poor RFS and OS, respectively (Table 4).

Neither MET protein expression nor MET amplification status showed a significant association with patient's survival (Table 4, Fig. 4). However, patients with MET-amplified tumor, defined by criteria of Schildhaus et al. [14] (method A), exhibited shorter OS compared to those with the nonamplified tumor (median OS, 26.8 months vs. 72.3 months). The median RFS of the patients with MET-amplified tumor was also shorter than those with the non-amplified tumor (median RFS, 16.0 months vs. 51.7 months). Similar results were observed with other criteria for MET amplification.

\section{Discussion}

MET is a transmembrane protein, which acts as a receptor of HGF. The binding of HGF to the MET protein triggers several downstream signaling pathways, including PI3K / AKT, MAPK, Wnt/ $\beta$-catenin, and STAT signaling pathways [19]. Activation of these pathways can drive various biological processes related to cancer, such as cell proliferation, migration, invasion, inhibition of apoptosis, epithelial to mesenchymal transition, and angiogenesis $[8,19]$. MET was first identified in a human osteosarcoma as an oncogene, in the form of TPR-MET fusion [20]. Then, dysregulation of MET protein and amplification had been found in several human malignancies including gastric [21], colorectal [22], breast [23], and NSCLC [10].

The oncogenic role of MET was also investigated in biliary tumors, including intra- and extrahepatic cholangiocarcinomas and GBCs. MET overexpression has been observed in the neoplastic glandular epithelium of furan-induced rat cholangiocarcinomas [24]. Previous studies with clinical samples have investigated MET expression by IHC and demonstrated that the prevalence of MET overexpression in GBCs 
was variable and ranged from $5 \%$ to $74 \%$ (Table 5) [25-29]. This variability might be due to the difference in primary antibodies used in IHC and interpretation criteria for overexpression. Moon et al. [28] revealed that MET overexpression was observed in $74 \%$ of the GBC cases and associated with invasion depth and increased staining intensity of MET at the invasive front of GBCs, which suggested their important role in tumor invasion [28]. However, Sanada et al. [27] found diffuse membranous staining of MET in the intraductal neoplastic components and no staining in the invasive components, suggesting that MET overexpression might be related to early events of carcinogenesis rather than tumor progression [27]. Yang et al. [26] found that MET overexpression correlated with adverse clinicopathological factors, such as lymph node metastasis, invasion, and decreased OS. In our study, MET overexpression was observed in $39.8 \%$ of GBCs. The interpretation criteria of overexpression used in this study was adopted from a previous clinical trial, which revealed that dual MET / EGFR inhibition was clinically beneficial in NSCLC only in the MET overexpression group. However, no significant correlation was observed between MET overexpression and clinicopathological features in our GBC cohort. We performed IHC and SISH on whole tissue sections in subset of cases. Although the different MET immunoreactivity and gene copy number is observed at different areas within tumor, there is no tendency of increased MET immunoreactivity or gene copy number at invasive front as compared to tumor center. Although some previous studies have found no clinicopathological significance of MET overexpression [25,29], other studies have shown significant correlation with worse prognostic factors [26,28]. These discrepancies might be due to different ethnicities of cohorts, the definition of overexpression used, and relatively small number of tumor samples.

Only one ISH study on the MET gene copy number in GBCs was found in the literature, and it revealed that no amplification was detected in 89 cases of GBCs [25]. The previous studies using NGS data reported that MET amplification was rare event in GBCs [30,31]. In our study, no MET amplification was detected by NGS method in 17 available cases. However, we found that $18.3 \%$ of GBCs showed MET amplification by ISH. This discrepancy between ISH and NGS methods for MET copy number evaluation may be resulted from intratumoral heterogeneity, contamination of non-neoplastic stromal and immune cells, and different threshold for detecting copy number alteration in high throughput data. However, the most important strength of tissue section based ISH method is that we can discriminate tumor cells from other non-neoplastic components. The tumor cellularity of GBC used in sequencing is generally low and usually less than $50 \%$. In the previous study, there have been reported intratumoral heterogeneity of MET expression in solid tumors $[32,33]$. We also identified intratumoral heterogeneity of MET expression and amplification on whole tissue sections.

MET amplification, regardless of interpretation criteria, showed significant association with the adverse clinicopathological features, including higher histological grade, advanced pT category, frequent lymph node metastasis, and advanced AJCC stage. Moreover, MET amplification showed a tendency to shorten OS and RFS, which were not statistically significant.

We investigated the correlation between MET protein expression and gene amplification. However, there was no correlation between MET protein overexpression and amplification, although the incidence of MET overexpression tended to be higher in tumors from patients with $M E T$ amplification than that in tumors from patients with no amplification. Some studies have shown lack of correlation between MET overexpression and gene amplification in HCC and NSCLC $[34,35]$. These studies and our results suggested that other than gene amplification, there are different mechanisms of protein overexpression. It can be inferred that the other mechanisms, including autocrine and paracrine HGF, increased expression of HGF activator, ligand-independent interactions with other receptors, interactions with other active cell-surface receptors and/or epigenetic regulation might play an important role in MET expression without genomic amplification [19,36,37]. Additionally, activation of other oncogenic factors, inactivation of tumor suppressors, such as TP53, and upregulated microRNAs have been known to enhance MET transcription [38].

In conclusion, the present study found that $M E T$ amplification was observed in approximately $20 \%$ of the GBCs, and that it was associated with adverse clinicopathological characteristics, such as histological grade, T category, lymph node metastasis, and AJCC stage. Further studies are needed to elucidate the significance of $M E T$ amplification as a potential therapeutic target and predictive biomarker for antiMET-targeted therapy in GBC patients.

\section{Electronic Supplementary Material}

Supplementary materials are available at Cancer Research and Treatment website (https://www.e-crt.org).

\section{Conflicts of Interest}

Conflict of interest relevant to this article was not reported.

\section{Acknowledgments}

This work was supported by a National Research Foundation of Korea (NRF) grant funded by the Korean government (Ministry of 
Science, ICT \& Future Planning) (NRF-2015R1C1A1A01056091) and Basic Science Research Program through the National Research Foundation of Korea (NRF) funded by the Ministry of Education
(NRF-2018R1D1A1B07048798). We would like to thank Sungwoong kim, Jeongyun Eom, and Jisook Kim (Department of Pathology, Hanyang University Hospital) for excellent technical assistance.

\section{References}

1. Jung KW, Won YJ, Kong HJ, Lee ES. Cancer statistics in Korea: incidence, mortality, survival, and prevalence in 2016. Cancer Res Treat. 2019;51:417-30.

2. Sharma A, Sharma KL, Gupta A, Yadav A, Kumar A. Gallbladder cancer epidemiology, pathogenesis and molecular genetics: recent update. World J Gastroenterol. 2017;23:3978-98.

3. Li M, Zhang Z, Li X, Ye J, Wu X, Tan Z, et al. Whole-exome and targeted gene sequencing of gallbladder carcinoma identifies recurrent mutations in the ErbB pathway. Nat Genet. 2014;46:872-6.

4. Bengala C, Bertolini F, Malavasi N, Boni C, Aitini E, Dealis C, et al. Sorafenib in patients with advanced biliary tract carcinoma: a phase II trial. Br J Cancer. 2010;102:68-72.

5. Chiorean EG, Ramasubbaiah R, Yu M, Picus J, Bufill JA, Tong $\mathrm{Y}$, et al. Phase II trial of erlotinib and docetaxel in advanced and refractory hepatocellular and biliary cancers: Hoosier Oncology Group GI06-101. Oncologist. 2012;17:13.

6. Vigna E, Naldini L, Tamagnone L, Longati P, Bardelli A, Maina F, et al. Hepatocyte growth factor and its receptor, the tyrosine kinase encoded by the c-MET proto-oncogene. Cell Mol Biol (Noisy-le-grand). 1994;40:597-604.

7. Blumenschein GR Jr, Mills GB, Gonzalez-Angulo AM. Targeting the hepatocyte growth factor-cMET axis in cancer therapy. J Clin Oncol. 2012;30:3287-96.

8. Birchmeier C, Birchmeier W, Gherardi E, Vande Woude GF. Met, metastasis, motility and more. Nat Rev Mol Cell Biol. 2003;4:915-25.

9. Furge KA, Zhang YW, Vande Woude GF. Met receptor tyrosine kinase: enhanced signaling through adapter proteins. Oncogene. 2000;19:5582-9.

10. Nakamura Y, Niki T, Goto A, Morikawa T, Miyazawa K, Nakajima J, et al. c-Met activation in lung adenocarcinoma tissues: an immunohistochemical analysis. Cancer Sci. 2007;98: 1006-13.

11. Suzuki K, Hayashi N, Yamada Y, Yoshihara H, Miyamoto Y, Ito $\mathrm{Y}$, et al. Expression of the c-met protooncogene in human hepatocellular carcinoma. Hepatology. 1994;20:1231-6.

12. Drilon A, Cappuzzo F, Ou SI, Camidge DR. Targeting MET in lung cancer: will expectations finally be MET? J Thorac Oncol. 2017;12:15-26.

13. Spigel DR, Ervin TJ, Ramlau RA, Daniel DB, Goldschmidt JH Jr, Blumenschein GR Jr, et al. Randomized phase II trial of Onartuzumab in combination with erlotinib in patients with advanced non-small-cell lung cancer. J Clin Oncol. 2013;31: 4105-14.

14. Schildhaus HU, Heukamp LC, Merkelbach-Bruse S, Riesner
K, Schmitz K, Binot E, et al. Definition of a fluorescence in-situ hybridization score identifies high- and low-level FGFR1 amplification types in squamous cell lung cancer. Mod Pathol. 2012;25:1473-80.

15. Cappuzzo F, Marchetti A, Skokan M, Rossi E, Gajapathy S, Felicioni L, et al. Increased MET gene copy number negatively affects survival of surgically resected non-small-cell lung cancer patients. J Clin Oncol. 2009;27:1667-74.

16. Tanaka A, Sueoka-Aragane N, Nakamura T, Takeda Y, Mitsuoka M, Yamasaki F, et al. Co-existence of positive MET FISH status with EGFR mutations signifies poor prognosis in lung adenocarcinoma patients. Lung Cancer. 2012;75:89-94.

17. Jurmeister P, Lenze D, Berg E, Mende S, Schaper F, Kellner U, et al. Parallel screening for ALK, MET and ROS1 alterations in non-small cell lung cancer with implications for daily routine testing. Lung Cancer. 2015;87:122-9.

18. Ou SH, Kwak EL, Siwak-Tapp C, Dy J, Bergethon K, Clark JW, et al. Activity of crizotinib (PF02341066), a dual mesenchymalepithelial transition (MET) and anaplastic lymphoma kinase (ALK) inhibitor, in a non-small cell lung cancer patient with de novo MET amplification. J Thorac Oncol. 2011;6:942-6.

19. Sierra JR, Tsao MS. c-MET as a potential therapeutic target and biomarker in cancer. Ther Adv Med Oncol. 2011;3(1 Suppl): S21-35.

20. Cooper CS, Park M, Blair DG, Tainsky MA, Huebner K, Croce $\mathrm{CM}$, et al. Molecular cloning of a new transforming gene from a chemically transformed human cell line. Nature. 1984;311:2933.

21. Li Y, Chen CQ, He YL, Cai SR, Yang DJ, He WL, et al. Abnormal expression of E-cadherin in tumor cells is associated with poor prognosis of gastric carcinoma. J Surg Oncol. 2012;106: 304-10.

22. Di Renzo MF, Olivero M, Giacomini A, Porte H, Chastre E, Mirossay L, et al. Overexpression and amplification of the met/HGF receptor gene during the progression of colorectal cancer. Clin Cancer Res. 1995;1:147-54.

23. Garcia S, Dales JP, Jacquemier J, Charafe-Jauffret E, Birnbaum D, Andrac-Meyer L, et al. c-Met overexpression in inflammatory breast carcinomas: automated quantification on tissue microarrays. Br J Cancer. 2007;96:329-35.

24. Radaeva S, Ferreira-Gonzalez A, Sirica AE. Overexpression of C-NEU and C-MET during rat liver cholangiocarcinogenesis: a link between biliary intestinal metaplasia and mucin-producing cholangiocarcinoma. Hepatology. 1999;29:1453-62.

25. Nakazawa K, Dobashi Y, Suzuki S, Fujii H, Takeda Y, Ooi A. Amplification and overexpression of c-erbB-2, epidermal 
growth factor receptor, and c-met in biliary tract cancers. J Pathol. 2005;206:356-65.

26. Yang L, Guo T, Jiang S, Yang Z. Expression of ezrin, HGF and c-met and its clinicopathological significance in the benign and malignant lesions of the gallbladder. Hepatogastroenterology. 2012;59:1769-75.

27. Sanada Y, Osada S, Tokuyama Y, Tanaka Y, Takahashi T, Yamaguchi K, et al. Critical role of c-Met and Ki67 in progress of biliary carcinoma. Am Surg. 2010;76:372-9.

28. Moon WS, Park HS, Lee H, Pai R, Tarnawski AS, Kim KR, et al. Co-expression of cox-2, C-met and beta-catenin in cells forming invasive front of gallbladder cancer. Cancer Res Treat. 2005;37:171-6.

29. Heo MH, Kim HK, Lee H, Kim KM, Lee J, Park SH, et al. The clinical impact of c-MET over-Expression in advanced biliary tract cancer (BTC). J Cancer. 2017;8:1395-9.

30. Narayan RR, Creasy JM, Goldman DA, Gonen M, Kandoth C, Kundra $\mathrm{R}$, et al. Regional differences in gallbladder cancer pathogenesis: Insights from a multi-institutional comparison of tumor mutations. Cancer. 2019;125:575-85.

31. Lee H, Ross JS. The potential role of comprehensive genomic profiling to guide targeted therapy for patients with biliary cancer. Therap Adv Gastroenterol. 2017;10:507-20.
32. Choi J, Lee HE, Lee HS, Han N, Kim MA, Kim WH. Evaluation of intratumoral and intertumoral heterogeneity of MET protein expression in gastric cancer. Appl Immunohistochem Mol Morphol. 2018;26:445-53.

33. Casadevall D, Gimeno J, Clave S, Taus A, Pijuan L, Arumi M, et al. MET expression and copy number heterogeneity in nonsquamous non-small cell lung cancer (nsNSCLC). Oncotarget. 2015;6:16215-26.

34. Lee SJ, Lee J, Sohn I, Mao M, Kai W, Park CK, et al. A survey of c-MET expression and amplification in 287 patients with hepatocellular carcinoma. Anticancer Res. 2013;33:5179-86.

35. Sun W, Song L, Ai T, Zhang Y, Gao Y, Cui J. Prognostic value of MET, cyclin D1 and MET gene copy number in non-small cell lung cancer. J Biomed Res. 2013;27:220-30.

36. Appleman LJ. MET signaling pathway: a rational target for cancer therapy. J Clin Oncol. 2011;29:4837-8.

37. Barat S, Bozko P, Chen X, Scholta T, Hanert F, Gotze J, et al. Targeting c-MET by LY2801653 for treatment of cholangiocarcinoma. Mol Carcinog. 2016;55:2037-50.

38. Duan Z, Choy E, Nielsen GP, Rosenberg A, Iafrate J, Yang C, et al. Differential expression of microRNA (miRNA) in chordoma reveals a role for miRNA-1 in Met expression. J Orthop Res. 2010;28:746-52. 